
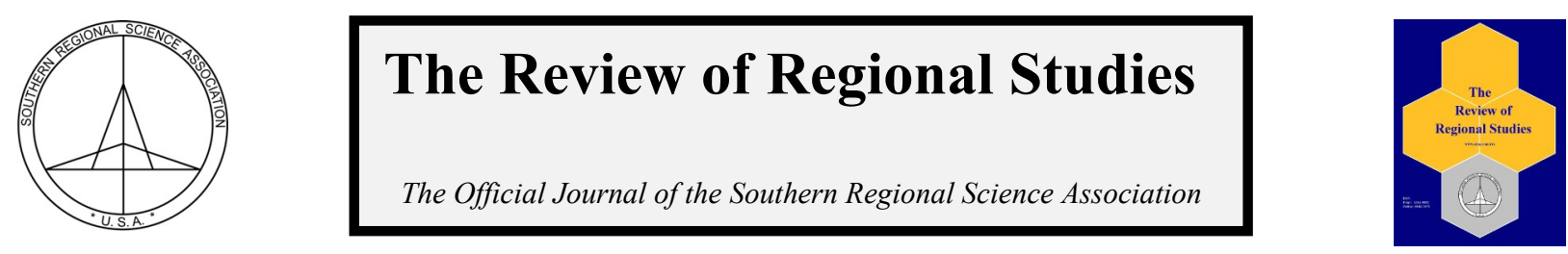

\title{
On the Macroeconomic Impact of a Regional Development Policy with Endogenous Residential Choice*
}

\author{
Juntip Boonprakaikawe and Frédéric Tournemaine
}

Faculty of Economics, Chulalongkorn University, Thailand

\begin{abstract}
This paper develops a simple two-region endogenous growth model in which individuals must choose where to reside and the government decides the amount of productive public investments for each area. In such a framework, we analyze the implications of a change in government's regional policy on individuals' residential choice, growth, inequality and welfare. In doing so, we put in evidence the key role played by the strength of congestion effects in production. When they are strong, we show that an increase in the amount of public infrastructure in the poor region not only increases growth and welfare but also reduces economywide inequalities. Therefore, there is no trade-off between growth, welfare and inequality. Interestingly, we also show that inequality can always be dampened if the development gap across regions is initially high.
\end{abstract}

Keywords: residential choice, public infrastructure, inequality, growth

JEL Codes: O41, R1

\section{INTRODUCTION}

Urbanization, whereby populations in rural areas migrate to cities, is a well-known and documented process which accompanies economic development. For instance, while there were only 5 cities with over five million people worldwide in the 1950s, recent estimates predict that there could be over 100 in 2030. Such a trend is the outcome of several factors, such as better wage and job opportunities, network facilities, transportation, schools, universities, and hospitals that cities offer compared to rural areas. Moreover, as pointed out by Henderson (2002), the urbanization process occurred differently in developed and developing countries. While it was relatively slow for developed countries, it took place more quickly in developing countries giving birth to mega-cities characterized by very high levels of concentration. ${ }^{1}$ Hansen (1990) explains that one reason for this feature is that, in the early stage of development, developing countries lack the necessary resources to provide productive public infrastructure in poor areas. On the one hand, it results in greater disparities between urban and rural areas fostering in turn the already very high concentration levels of mega-cities. ${ }^{2}$ On the other hand, it can generate high negative externalities on individuals' welfare and productivity due to congestion effects:

\footnotetext{
* We thank Matthew Benton, Vasileios Zikos, and two anonymous referees for their comments and suggestions. We gratefully acknowledge financial support from the Thailand Research Fund.

Juntip Boonprakaiakawe and Frédéric Tournemaine are Assistant and Associate Professors of Economics at Chulalongkorn University, Pathumwan, Bangkok, Thailand. Corresponding Author: F. Tournemaine. e-mail: frederic.tournemaine@gmail.com

${ }^{1}$ The author explains that the process took about one century in the US while it took only twenty years in Korea.

${ }^{2}$ See, e.g., Martin and Ottaviano (2001) who establish the link between geographical agglomeration, regional income inequalities and growth. They show that economic agglomeration and growth have a positive impact on each other.
}

(C) Southern Regional Science Association 2014.

ISSN 1553-0892, 0048-749X (online)

www.srsa.org/rrs 
these take, for example, the form of pollution that affect individuals' health, living cost, and space and time to commute. ${ }^{3}$

A noteworthy feature of these costs is that they increase with city size (see, e.g., Puga, 1999). As a consequence, in a context where, as explained by Cadena et al. (2011), most megacities in the developing countries of Latin America have outgrown the capacity of their infrastructures, resulting in a loss of efficiency. More importantly, the authors argue that, beyond a critical size, the potential benefits of agglomeration are surpassed by the costs it generates. It can then explain the lower level of growth of some mega-cities in Latin America, such as São Paulo or Rio de Janeiro in Brazil, compared to the national level. As noted by Cadena et al., given the importance of mega-cities in generating national income of developing countries, a possible implication of such trend could be a slowdown in economic development. Therefore, not only are these issues of interest, namely the interaction between growth, inequality, migration choice and welfare, but also, it appears important to formalize them in a unified framework to fully understand the mechanisms at work.

In this paper, we bring together the theme of regional development and those of migration, growth, and distribution that are themselves endogenously determined. Although some articles have tackled these issues, none has analyzed their interaction in a unified framework. We are thus able to assess the consequences of a change in government's economic policy in terms of public infrastructure investments on individuals' choice of residence, growth, inequality and welfare.

Investments in public infrastructure are numerous. Among other things, these include the funding of education (schools), healthcare (hospitals), security (police and army), environmental protection (green areas), and basic needs such as access to electricity, clean water and, sanitation. In the present paper, we use the generic term public infrastructure to emphasize transportation infrastructure. The reason is that among the costs of production agglomeration, expenditure related to transportation is one of the most prominent. ${ }^{4}$ In a nutshell, we argue that, in the case of mega-cities of developing countries where, as mentioned above, congestion costs outweigh the benefits of agglomeration, increasing the share of public funds allocated to poorer regions to favor their development could be the right policy to implement.

A novelty of this paper is to analyze policy effects through the channel of individuals' decisions to migrate from one region to another. That is, in the spirit of the arguments given above and by Boarnet (1998) who, contrary to us, has a static framework, we share the view of the important role played by public infrastructure investments on the mobility of production factors and as a tool to boost the economic development of a region. To proceed, we formalize a trade-off for individuals between income (or consumption) and disutility due to congestion effects and consider the case where the government decides to favor the development of poor areas in order to reduce concentration in mega-cities. ${ }^{5}$

\footnotetext{
${ }^{3}$ Van der Ploeg and Poelhekke (2008, pp. 484-485) explain for instance that "[S]ome mega-cities may be too large and suffer from slums, pollution and other congestion problems." Furthermore, the problem of managing mega-cities can add to inefficiency (see Cadena et al., 2011, for a discussion of Latin America countries).

${ }^{4}$ One could also include services such as water and electricity. Even healthcare service can indirectly affect production efficiency. Different types of public infrastructure will, in reality, have different levels of impact. Here, for simplicity, we assume a unified level of impact, one for production congestion and another for utility congestion.

${ }^{5}$ Although this paper deals with similar issues, it is not related to the new theories of economic geography initiated by such authors as Krugman (1991) and Krugman and Venables (1995).
}

(C) Southern Regional Science Association 2014. 
The idea of public infrastructure as a possible development strategy, which goes back at least to Hirschman (1958), has been the subject of intensive research. Empirical analyses by Aschauer $(1989,2000)$ and Rioja $(1999,2005)$ establish that public infrastructure investments (such as road networks, bridges, water, or electric supply systems) play an important role for growth. Others, such as Holtz-Eakin (1994) and Holtz-Eakin and Schwartz (1995) suggest that there is no evidence of such a result. Between these two extremes, some like Evans and Karras (1994) show a strong relationship between productivity and public spending in education but cannot find any between productivity and other kinds of public spending. Although we cannot rule on this ongoing debate, in this paper we follow the first strand of the literature, as well as the growth theory initiated by Barro (1990), in assuming the key role of government expenditures for economic development. ${ }^{6}$ Referring to Rioja (1999) and Alonso-Carrera, Freire-Seren, and Manzano (2009) among others, we can point out that the disagreement found in the literature might come from, among other things, the use of disaggregated data. That is, it is possible that the full productivity gains of public goods and services provided by the government are not well captured because they benefit the whole economy. ${ }^{7}$

The contribution of the present article is multifaceted. As we put the location choice of individuals at the center of the analysis, the present work shares some similarities with the standard monocentric model (Alonso, 1964; Mills, 1967; Muth, 1969). However, we do not formalize any commuting costs and land prices. Thus, given its endogenous growth structure and its focus on the macroeconomic impact of public spending across different regions, it appears closer to another strand of the literature by de la Fuente and Vives (1995), Zhang (1997), Alonso-Carrera, Freire-Seren, and Manzano (2009), Ott and Soretz (2010), and Arcalean, Glomm, and Schiopu (2012). In particular, de la Fuente and Vives (1995) show that government's investments in training and infrastructure may be important tools to reduce regional disparity. However, their analysis remains silent about the optimal level of regional redistribution. In the present paper, in contrast, we discuss and characterize the set of policy instruments that maximize welfare both at the national and regional levels.

In the same spirit, Alonso-Carrera, Freire-Seren, and Manzano (2009) examine the impact of public infrastructure spending on regional disparities. They argue that favoring the development of poor regions can lead to sub-optimal levels of income because those regions have lower profitability. Interestingly, our framework shows that this result can be overturned if we allow individuals to choose their location of residence by taking into account the negative impacts generated by a more crowded region (i.e., productivity and welfare losses due to congestion effects). This is an important issue in light of empirical results by Ciccone and Hall (1996) and Casella (2005) showing the importance of geographical location in terms of population size and concentration of economic activity to explain productivity differentials.

Arcalean, Glomm, and Schiopu (2012) study the growth effects of regional distribution taking into account the possibility of migration of individuals. Contrary to our analysis, however,

\footnotetext{
${ }^{6}$ See also, for instance, the recent contribution by Agenor (2008) on the role of government spending for economic development. He tackles the problem of optimal allocation of government spending between productive public infrastructure and health in a one-sector endogenous growth model à la Barro (1990). Although a trade-off can exist between various types of spending at the government level, the author demonstrates the important role played by government spending in providing public infrastructure and sustaining long-term growth.

${ }^{7}$ For more details on this debate, interested readers can refer to the comprehensive discussion by Munnell (1992) or to the critical survey by Romp and De Haan (2007).
}

(C) Southern Regional Science Association 2014. 
they do not formalize the idea of heterogeneous development across regions. Therefore, they overlook the policy implications on inequality.

Following Zhang (1997), we develop a standard endogenous growth model with two heterogeneous regions. Like Zhang, heterogeneity between regions stems from their initial level of development which is captured by their exogenous level of productivity. In other words, the production possibilities are specific to each region. The main difference is that, in our paper, production possibilities depend on population migration which is itself affected by government's production of public infrastructure. Therefore, we are able to investigate the issue of regional inequality and welfare in the presence of both production and utility congestion. These are issues absent in Zhang's work. In that sense, the present framework complements the recent contribution by Ott and Soretz (2010), who explore the potential impact of regional policy on the spatial distribution of economic activity. The critical difference is that our focal point is the examination of individuals' choice to relocate through the channel of public policy on infrastructure.

Among the key findings of this paper, we show that the strength of welfare and productivity losses due to congestion play an important role regarding the implications of interregional policy changes. For sufficiently high congestion effects, such as those we might observe in mega-cities of developing countries, we show that favoring the development of the poor region is the most desirable policy. The intuition is that such a policy leads to productivity gains in the rich region via the reduction of congestion effects it induces. In other words, the policy acts via individuals' decision to relocate from the rich to the poor region. Interestingly, in the case of an initially high level of inequality across regions, the government is likely to also reduce the economywide level of inequality. In other words, if congestion costs are high as it is likely to be the case in mega-cities of developing countries, we show that public infrastructure investments in the poorest areas not only does not jeopardize growth but also, together with improvements in welfare of individuals, comes lower income inequality.

The remainder of the paper is organized as follows. In Section 2, we present the model. In Section 3, we characterize the equilibrium and discuss its main properties. Notably, we examine the policy implications of favoring the development of the poor region for population migration, long-term growth, economywide inequality and welfare. We conclude in Section 4.

\section{MODEL}

Consider a closed economy in continuous time, denoted by $t$, which has an infinite nonnegative horizon. The economy is populated by a constant and exogenous mass $[0, L]$ of infinitely lived and identical individuals who must decide where to reside. Only two possible locations (regions) are available, denoted by $j$, where $j=1,2$. We assume that region 1 benefits from a larger scale of technology than does region 2. As we will see shortly, it is formalized by a greater productivity of individuals if they decide to reside in region 1, which in turn allows them to generate higher income, consumption, and capital levels than region 2. We also assume that rising population size in a given region negatively affects individuals' welfare (see below). In other words, we formalize a trade-off between income, wealth, and consumption on the one hand and living space (or utility congestion), ${ }^{8}$ formalized through population size, on the other hand.

\footnotetext{
${ }^{8}$ It is typically difficult to distinguish between production and consumption infrastructure. A single type of infrastructure, such as roads, may affect congestion in both kinds of economic activity, albeit differently. Here, we allow for different levels of
}

(C) Southern Regional Science Association 2014. 
This formalization will allow us to endogenize the choice of region by individuals - i.e., the shares of individuals opting for region 1 or region 2-and to analyze the implication of a policy change on these values.

The rest of the model is standard and mainly follows from Barro (1990). We assume that each individual, denoted by $i \in[0, L]$, living in region $j=1,2$ is initially endowed with $k_{i j, 0}$ units of physical capital (wealth) and one unit of labor time. She produces an output that can be consumed, invested to give new units of capital, and used to purchase public goods and services in the form of public infrastructure. Technologies and preferences are described below.

Each individual $i$ living in region $j$ produces output via an individual stock of private capital and a region-specific amount of government spending on public infrastructure, both of which are subject to congestion:

$$
y_{i j, t}=A_{j}\left(k_{i j, t}\right)^{\alpha}\left[\frac{\gamma_{j, t}}{\left(p_{j, t} L\right)^{v}}\right]^{1-\alpha}, i \in[0, L], j=1,2
$$

where $0<\alpha<1,0<v<1 /(1-\alpha), A_{j}>0$ is a time-invariant parameter specific to region $j, k_{i j, t}$ is individual $i$ 's allocation of physical capital required while in region $j, \gamma_{j, t}$ is the current level of government spending on infrastructure in region $j$, and $p_{j, t}$ represents the share of individuals living in region $j$ and thus verifies $p_{1, t}+p_{2, t}, i \in[0, \mathrm{~L}], j=1,2$.

Following Beauchemin (2001) and Agenor (2005), among others, technology (1) captures the idea that, due to congestion effects, which is reflected by $v$, public infrastructure becomes less productive when used by a labor force of greater size. ${ }^{9}$ We define congestion effects to be low when $0<v \leq 1$ and strong when $1<v<1 /(1-\alpha)$. When $0<v<1$, public infrastructure is, to a certain extent, nonrivalrous. When $v=1$, productivity depends on per capita public spending. If $1<v<1 /(1-\alpha)$, the rising size of a labor force has an inversely proportional effect on production. It is of interest to note that strong congestion effects reflect the situation of overpopulated cities (mega-cities), where further increases in population or the number of workers can harm production efficiency, eventually leading to negative scale effects. ${ }^{10}$ The upper-bound on $v$ ensures that more-populated regions produce more output. ${ }^{11}$

congestion effects on production and utility but implicitly assume that all types of infrastructure affecting production (utility) have the same level of congestion effect on production (utility).

${ }^{9}$ If we set $v=0$, we recover the standard technology of production of output (see, e.g., Barro and Sala-i-Martin, 2004). In this case, public infrastructure is completely nonrivalrous; the benefit on individual's production does not decline with usage volume.

${ }^{10}$ For example, when road traffic doubles, it may not be possible (or cost too much) to double the road surface. In addition, a problem of managing mega-cities can also add to inefficiency (see Cadena et al., 2011, for a discussion on Latin America countries).

${ }^{11}$ As individuals living in the same region end up with the same level of output, capital, and consumption at the steady state (i.e. $y_{i j, t}=y_{j, t}, k_{i j, t}=k_{j, t}, c_{i j, t}=c_{j, t}$ for all $i \in[0, L]$ and $j=1,2$ from (1), aggregate production in region $j$ is given by:

$p_{j, t} L y_{j, t}=A_{j}\left(p_{j, t} L k_{j, t}\right)^{\alpha}\left[\left(p_{j, t} L\right)^{1-v} \gamma_{j, t}\right]^{1-\alpha}=A_{j}\left(p_{j, t} L\right)^{1-v(1-\alpha)}\left(k_{j, t}\right)^{\alpha}\left(\gamma_{j, t}\right)^{1-\alpha}$.

That is, $\partial\left(p_{j, t} L y_{j, t}\right) / \partial\left(p_{j, t} L\right)>0$ is verified at the aggregate level although we have $\partial y_{i j, t} / \partial\left(p_{j, t} L\right)<0$ at the individual level, $i \in[0, L], \quad j=1,2$.

(C) Southern Regional Science Association 2014. 
It is possible to argue that congestion effects across regions should be different, i.e., $v_{1} \neq v_{2}$. For simplicity, however, we derive the main properties of the model in the simple case where $v_{1}=v_{2}=v$, and focus on the most interesting case where congestion effects are strong. There are two reasons for this choice. First, this particular scenario is most interesting as it yields new results and insight to the issue of interregional policy's effects. Second, in Appendix A.4 we do, in fact, also discuss the results in a model where $0<v_{2}<1<v_{1}$, i.e., we formalize a scenario in which congestion effects are strong in region 1 but low in region 2 . Beyond the technical difficulties that such formalization implies, we show that the main results of the simpler model are not affected.

Further, in the same spirit as Eaton and Eckstein (1997), technology (1) captures the idea that individuals benefit from a different level of technology depending on where they decide to reside. This can be due to historical reasons. For instance, activities have mainly developed in region 1 because of its proximity to a natural resource such as a river or a fertile land. Closer to the spirit of this paper, we could also argue that $A_{1}$ and $A_{2}$ stand for the quality of infrastructure provided in each region. In other words, infrastructure in each region is heterogeneous and $A_{1}$ and $A_{2}$ stand for their respective productivities. Without loss of generality, we assume a larger scale of technology in region 1 than in region $2: A_{1} \geq A_{2}$, meaning that, other things equal, each individual can produce a greater amount of output in region 1 than in region 2 .

We assume that public infrastructure is financed through a flat tax rate, $\tau$, that is levied on each individual's production (effectively an income tax): $\gamma_{t}=\tau\left(\int_{0}^{p_{1, t} L} y_{i 1, t} d i+\int_{p_{1, t}}^{L} y_{i 2, t} d i\right)$. For notational convenience, we denote the share of the tax that finances public infrastructure in region $j$, by $\varepsilon_{j}$ so that $\gamma_{j, t}=\varepsilon_{j} \tau_{t}$, for $j \in[1,2]$ at each instant, with: $1=\varepsilon_{1}+\varepsilon_{2}$. For the sake of simplicity, we consider public infrastructure as a flow variable rather than a stock. We show in Appendix A.2 that the two approaches yield exactly the same qualitative results. As we will see below, the noteworthy feature of the model is that, in affecting the relative values of $\gamma_{1, t}$ and $\gamma_{2, t}$, via a change in the repartition $\varepsilon_{1}$ and $\varepsilon_{2}$, the government can affect the location choice of individuals, growth and distribution.

Assuming that each unit of output devoted to investments yields one new unit of capital, the resource constraint of an individual is given by

$$
(1-\tau) y_{i j, t}=c_{i j, t}+\dot{k}_{i j, t}+\delta k_{i j, t}, \quad i \in[0, L], \quad j=1,2
$$

where $\delta>0$ is the depreciation rate of physical capital. Preferences of individuals are represented by the utility function

$$
U_{i j, t}=\int_{0}^{\infty}\left[\ln c_{i j, t}-\eta \ln \left(p_{j, t} L\right)\right] e^{-\rho t} d t, \quad i \in[0, L], \quad j=1,2
$$

where $\rho>0$ is the rate of time preference, $\eta>0$ is a time-invariant parameter measuring the negative impact of population size, $p_{j, t} L$, on individual's utility, the latter being taken as given by each individual. ${ }^{12}$ That is, following Ciccone and Hall (1996), Casella (2005), and Arcalean,

\footnotetext{
${ }^{12}$ It is possible to conduct the analysis in the more general case of a constant elasticity of substitution utility function of the form: $U_{i j, t}=\int_{0}^{\infty}\left\{\left[c_{i j, t}\left(p_{j, t} L\right)^{-\eta}\right]^{(1-\sigma)}-1\right\} e^{-\rho t} /(1-\sigma) d t$, where $\sigma>0$. We do not do so, as it would unnecessarily complicate the analysis without modifying the results. We thus assume that $\sigma$ tends to one so that this formulation corresponds to (3).
}

(c) Southern Regional Science Association 2014. 
Glomm, and Schiopu (2012), we assume that individuals incur disutility (welfare cost) through a congestion effect, that is determined by the number of individuals who reside in the region. The welfare costs can take several forms. For instance, a greater population size in a given area is synonymous with greater levels of pollution, a reduction of available space for housing, a greater amount of time to spend in traffic jams to commute to work that can take away potential leisure time, and so on. We will see below that this parameter plays an interesting role regarding to our results.

\section{EQUILIBRIUM}

We proceed in three steps. First, we solve the maximization problem of individuals taking their location as given. Second, we determine their choice of location. Third, we characterize the steady state and analyze its properties. ${ }^{13}$

\subsection{Efficiency Conditions}

Given her location, each individual chooses consumption and wealth to maximize (3) subject to (1)-(2). After manipulation, the current-value Hamiltonian of this problem for individual $i$, living in location $j, i \in[0, L], j=1,2$, is:

$$
C V H_{i j, t}=\ln c_{i j, t}-\eta \ln \left(p_{j, t} L\right)+\lambda_{i j, t}\left[(1-\tau) A_{j}\left(k_{i j, t}\right)^{\alpha}\left[\gamma_{j, t} /\left(p_{j, t} L\right)^{\nu}\right]^{1-\alpha}-c_{i j, t}-\delta k_{i j, t}\right], i \in[0, L], j=1,2
$$

where $\lambda_{i j, t}$ is the co-state variable associated with (2). The first order conditions are: $\partial C V H_{i j, t} / \partial c_{i j, t}=0$ and $\partial C V H_{i j, t} / \partial k_{i j, t}=-\dot{\lambda}_{i j, t}+\lambda_{i j, t} \rho$.

The transversality condition is: $\lim _{t \rightarrow \infty} \lambda_{i j, t} k_{i j, t} e^{-\rho t}=0$. Rearranging the first order conditions, we obtain:

$$
\begin{aligned}
& \frac{1}{c_{i j, t}}=\lambda_{i j, t}, \quad i \in[0, L], j=1,2 \\
& \frac{\alpha(1-\tau) y_{i j, t}}{k_{i j, t}}-\delta+\frac{\dot{\lambda}_{i j, t}}{\lambda_{i j, t}}=\rho \quad i \in[0, L], \quad j=1,2 .
\end{aligned}
$$

Expression (4) states that the marginal utility of an extra unit of consumption equals the shadow price of wealth, while expression (5) states that the return to capital equals the discount rate $\rho$.

\subsection{Choice of Residence}

Having set out the individual's optimization problem conditional on their choice of region, we now determine which region the individual actually chooses. To avoid complexity, we assume that the choice between the two regions is made at time zero. Thus, we have: $p_{t}=p^{*}$ at each instant, where the symbol ${ }^{*}$ is used to denote any equilibrium variable and time subscripts are dropped when quantities are constant, but are kept for individual, perpetually growing,

\footnotetext{
${ }^{13}$ Like Zhang (1997), a crucial assumption we make is that physical capital owned by individuals is immobile across regions and moves across regions when the owner decides to change residence. This follows the arguments of Banerjee and Munshi (2004), Boyreau-Debray and Wei (2005) and Sharma (2008) who explain that, in developing economies (at the centre of our analysis), factors such as community identity and the nature of social ties, local government interference and capital market imperfections, are keys in determining the pattern of investments in a region and participate to the segmentation of the capital market. Moreover, as we will see, such assumption greatly simplifies the closing of the two-region framework as, in this case, the stationary distributions of physical capital, income, and consumption across regions are determinate.
}

(C) Southern Regional Science Association 2014. 
variables. This assumption presupposes perfect foresight, a feature which is in line with the deterministic nature of our model. ${ }^{14}$

To proceed, we compare the level of utility attained for individuals in each region. In the same spirit as the standard urban monocentric literature where spatial equilibrium requires that individuals must be indifferent across locations (see, e.g., Alonso, 1964; Mills, 1967, Muth, 1969), in our model any individual $i, i \in[0, L]$, must be indifferent between region 1 and 2 . Using (3), this means that the following condition must be verified:

$$
\int_{0}^{\infty}\left[\ln \left(\frac{c_{1, t}}{c_{2, t}}\right)-\eta \ln \frac{p^{*}}{1-p^{*}}\right] e^{-\rho t} d t=0 .
$$

Expression (6) captures the two effects of the long run: consumption considerations favor region 1 where infrastructure is higher; but other welfare considerations such as the available living space, formalized here via the population living in a given area, favor region 2. Had Equation (6) been greater (lower) than zero, the utility from living in region 1 (2) would be greater. In other words, $p^{*}$ adjusts so that the welfare of individuals is exactly the same whether they live in region 1 or 2: while those who join region 1 (2) have a higher (lower) level of consumption than those who live in region 2 (1), they also bear a more (less) crowded region (see Proposition 1 in the next sub-section).

The implication of this is twofold. First, individuals are identical; so when migration arises, it is effectively anonymous. ${ }^{15}$ Second, despite its structure, the model contains a period of dynamic adjustment before reaching a balanced growth path. Sustainable growth comes from the same mechanism as in Barro (1990): technologies exhibit constant returns to scale on reproducible inputs at the societal level because the government's budget constraint leads public infrastructure to depend on private capital. In Barro (1990), however, this mechanism generates a constant marginal productivity of capital in equilibrium, so that the aggregate economy does not exhibit transitional dynamics: it is initially placed on the balanced growth path. In the present framework, public infrastructure in one region is funded with taxes collected in the other region. Besides its redistributive implication, this also implies that the marginal productivity of the capital installed in one region depends on the capital installed in the other region. As the scale of productivity in each region is different $\left(A_{1}>A_{2}\right)$, this means that, along the adjustment path, the growth rates of variables in the two regions are likely to be different. For simplicity, the analysis of the transitional dynamics is relegated to Appendix A.3 because it does not bring much to the core analysis. So, in the remainder of the paper, we focus on the steady-state solution.

\footnotetext{
${ }^{14}$ Changing location in the middle of life would mean that the individual did not realize he/she made a mistake in his/her location choice in the first place. In the deterministic context of our model, such mistakes cannot occur; agents are perfectly informed (in particular about policy) and have perfect foresight.

${ }^{15}$ A natural extension would be to assess the kind of migration we would obtain if we consider a model where individuals are differentiated, for instance by innate skills for output production. Though interesting, this issue goes beyond the scope of this paper. Thus, it is left for future research. Still, we can point to Glaeser and Gyourko (2005) who argue that individuals who stay in declining urban areas are more likely to have lower set of skills.
}

(C) Southern Regional Science Association 2014. 


\subsection{Steady State}

\subsubsection{Characterization}

It is worth mentioning that, in a steady state, the growth rate of variables must be common across individuals. This property follows directly from inspection of (6), given that the shares of individuals in each region is constant. As a result, all the key ratios, like relative consumption among individuals but also their consumption-to-capital and output-to-capital, are constant (see Appendix A.1 for the details of the computations). Using this property, we can determine the share of individuals in each region (i.e., individuals' location choice), the common long-run level of growth of consumption, income, and capital, denoted by $\mathrm{g}^{*}$ and the economywide level of inequality defined as the variance of relative income to the average denoted by $\sigma_{y}^{2} \equiv \operatorname{Var}\left(y_{i j, t} / \overline{y_{t}}\right)$.

Straightforward computations relegated in Appendix A.1 lead to four key relationships arranged in Proposition 1, where the steady-state consumption, income and capital ratios of any individual living in region 1 over any individual living in region 2 , are respectively denoted by $\widetilde{c}^{*} \equiv c_{i 1, t} / c_{i 2, t}, \tilde{y}^{*} \equiv y_{i 1, t} / y_{i 2, t}, \widetilde{k}^{*} \equiv k_{i 1, t} / k_{i 2, t}, i \in[0, L]$.

Proposition 1: There exists a unique steady-state equilibrium in which a constant share of population given by

$$
\frac{1}{2}<p^{*}=\frac{\left[\frac{A_{1}\left(\varepsilon_{1}\right)^{1-\alpha}}{A_{2}\left(\varepsilon_{2}\right)^{1-\alpha}}\right]^{\frac{1}{(v+\eta)(1-\alpha)}}}{1+\left[\frac{A_{1}\left(\varepsilon_{1}\right)^{1-\alpha}}{A_{2}\left(\varepsilon_{2}\right)^{1-\alpha}}\right]^{(v+\eta)(1-\alpha)}}<1,
$$

chooses to reside in region 1; the remaining share $1-p^{*}$ locates in region 2 . The consumption, income and capital ratios of any individual living in region 1 over any individual living in region 2, are all equal and given by:

$$
\widetilde{c}^{*}=\widetilde{y}^{*}=\widetilde{k}^{*}=\left[\frac{A_{1}\left(\varepsilon_{1}\right)^{1-\alpha}}{A_{2}\left(\varepsilon_{2}\right)^{1-\alpha}}\right]^{\frac{\eta}{(v+\eta)(1-\alpha)}}>1 .
$$

The common level of growth of output, capital and consumption is given by:

$$
g^{*}=\alpha(1-\tau)(\tau)^{\frac{(1-\alpha)}{\alpha}}\left\{\begin{array}{c}
\left(p^{*} L\right)^{1-v}\left(A_{1}\right)^{1 /(1-\alpha)} \varepsilon_{1} \\
+\left[\left(1-p^{*}\right) L\right]^{1-v}\left(A_{2}\right)^{1 /(1-\alpha)} \varepsilon_{2}
\end{array}\right\}^{\frac{(1-\alpha)}{\alpha}}-\delta-\rho
$$

The economywide level of inequality is given by:

$$
\sigma_{y}^{2}=p^{*}\left(1-p^{*}\right)\left[\frac{1-\widetilde{y}^{*}}{p^{*} \widetilde{y}^{*}+\left(1-p^{*}\right)}\right] .
$$

Proof: See Appendix A.1.

Equation (7) readily reveals that region 1 has a larger population than region 2 as long as the reverse relative share of public spending $\varepsilon_{2} / \varepsilon_{1}$ is not so large as to offset the effect of the relative scale of technology $A_{1} / A_{2}$. We have: $p^{*}>1 / 2$, if $\widetilde{A}=\left[A_{1}\left(\varepsilon_{1}\right)^{1-\alpha}\right] /\left[A_{2}\left(\varepsilon_{2}\right)^{1-\alpha}\right]>1$, where $A_{j}\left(\varepsilon_{j} \tau\right)^{1-\alpha}$ represents a measure of the development level of region $j, j=1,2$, and the ratio $\tilde{A}$ can be interpreted as the relative development level of the regions considered. Throughout the paper, we assume that $\widetilde{A}>1$. Interestingly, this allows us to ensure that individuals residing in region 1 produce a greater amount of output than those in region 2 . Thus, we capture the

(C) Southern Regional Science Association 2014. 
observation that, in developing countries, mega-cities contribute proportionally more to aggregate production (see, e.g., Cadena et al., 2011).

Moreover, this implies that the relative quality of infrastructure across regions is a key factor behind the population distribution (see, e.g. Henderson, 1982; Roback, 1982). Condition (8) shows effectively that the welfare benefits of living in region 1 instead of region 2 depend on the relative development level of the regions, $\widetilde{A}$, too. In other words, while the benefits of a higher production (and in turn income) are attractive for individuals, the other side of the story is that a more crowded region endures higher congestion effects on both production, $v$, and utility, $\eta$. This is the mechanism which leads to the adjustment of the population across regions, $p^{*}$, and generates relative differences in consumption, income and capital, i.e., $\widetilde{c}^{*}=\widetilde{y}^{*}=\widetilde{k}^{*}>1$.

As shown in Appendix A.1, the economywide variance (10) is given as a weighted measure of the income gap between the two regions. This is because individuals are identical and obtain the same level of income if they choose to reside in the same region. Therefore, the term $p^{*}\left(1-p^{*}\right)$ on the right hand side of (10) gives a measure of the relative weight of both regions in the determination of the economywide level of inequality and the term in square brackets is the measure of the income gap between regions. Interestingly, in the particular case where there is no disutility from congestion $(\eta=0)$, individuals in both regions end up with the same income, consumption and capital levels: $\widetilde{c}^{*}=\widetilde{y}^{*}=\widetilde{k}^{*}=1$. However, we still have $1 / 2<p^{*}<1$. In other words, parameter $\eta$ is crucial to capture regional imbalances, and parameter $v$ to regulate the relative productivity in both regions. With this in mind, it is interesting to analyze the properties of the model with respect to a change in the strength of congestion effects either on the production side, $v$, or preference side, $\eta$. This task is carried out next.

\subsubsection{Comparative Statics}

We analyze the effects of a change in the strength of the welfare cost and productivity loss due to the congestion effect (population size), captured by parameters $\eta$ and $\nu$, respectively. For clarity, we first discuss the effects on population shares, $p^{*}$ and $1-p^{*}$, and relative income, consumption and capital, $\widetilde{c}^{*}, \tilde{y}^{*}, \widetilde{k}^{*}$. Then, we turn to the outcome on growth, $g^{*}$, and economywide variance, $\sigma_{y}^{2}$.

Examination of Equations (7) and (8) shows that a greater marginal disutility from population size, $\eta$, leads to an increase in $\widetilde{c}^{*}, \widetilde{y}^{*}, \widetilde{k}^{*}$ and a reduction in $p^{*}$. The intuition is that as $\eta$ increases, region 1 (already more crowded than region 2 ) becomes less attractive. Therefore, some individuals move to region 2 even if their income, consumption, and capital perspectives are lowered.

In the same way, we can easily check that a more stringent congestion effect in output production, $v$, leads to a diminution of $p^{*}, \widetilde{c}^{*}, \tilde{y}^{*}, \widetilde{k}^{*}$. The reason is that a larger $v$ has a greater relative effect in region 1 , which is already more crowded than in region 2 . As a result, $\widetilde{c}^{*}, \tilde{y}^{*}, \widetilde{k}^{*}$ shrink and some individuals move from region 1 to region 2 .

To understand the growth effect of a positive change in $\eta$ and $v$, we can use (9) to obtain the following conditions: 


$$
\frac{\alpha}{1-\alpha} \frac{\left(g^{*}+\delta+\rho\right)^{\frac{\alpha}{1-\alpha}-1}}{L^{1-\nu}[\alpha(1-\tau)] \frac{\alpha}{1-\alpha}} \frac{d g^{*}}{d \eta}=(1-v)\left(1-p^{*}\right)^{-v}\left(A_{2}\right)^{1 /(1-\alpha)} \varepsilon_{2} \tau \frac{d p^{*}}{d \eta}\left(\tilde{y}^{*}-1\right),
$$

and

$$
\frac{\alpha}{1-\alpha} \frac{\left(g^{*}+\delta+\rho\right)^{\frac{\alpha}{1-\alpha}-1}}{L^{1-v}[\alpha(1-\tau)]^{\frac{\alpha}{1-\alpha}}} \frac{d g^{*}}{d v}=\left\{\begin{array}{l}
-\left(1-p^{*}\right)^{1-v}\left(A_{2}\right)^{1 /(1-\alpha)} \varepsilon_{2} \tau \operatorname{Ln}\left[\left(1-p^{*}\right) L\right] \\
\left.\times\left[\left(\tilde{y}^{*}\right)^{(1+\eta) / \eta} \frac{\operatorname{Ln}\left(p^{*} L\right)}{\operatorname{Ln}\left[\left(1-p^{*}\right) L\right.}\right]^{-1}\right] \\
(1-v)\left(1-p^{*}\right)^{-v}\left(A_{2}\right)^{1 /(1-\alpha)} \varepsilon_{2} \tau \frac{d p^{*}}{d v}\left(\tilde{y}^{*}-1\right)
\end{array}\right\} .
$$

For (11), given that $d p^{*} / d \eta<0$ and $\widetilde{y}^{*}>1$, we observe that, if congestion effects in production are large enough, i.e. $1<v<1 /(1-\alpha)$, the effects on growth are positive. Intuitively, the reduction in population size in region $1\left(d p^{*} / d \eta<0\right)$ becoming by definition less crowded, leads to an increase in individuals' productivity. This translates into an increase of aggregate savings and thus: $d g^{*} / d \eta>0$.

The growth effect of a change in $v$ is less clear-cut. From (12), $v$ affects growth negatively via its impact on the contribution of each region in the determination of aggregate growth (first term on the right-hand side) and positively via the migration effect it induces (second term on the right hand side). Although, $d g^{*} / d v$ can, in theory, be of either sign, it seems that $d g^{*} / d v<0$ is more likely to be the outcome we should observe: if congestion effects become stronger, this is indeed likely to reduce further the productivity of individuals in output production and in turn to reduce aggregate savings.

We now turn to the analysis of the impact of a change in $\eta$ or $v$ on economywide variance, $\sigma_{y}^{2}$ From our previous discussions, results are straightforward and intuitive. Examination of (10) with the fact that $d p^{*} / d \eta<0$ and $d \widetilde{y}^{*} / d \eta>0$, necessarily implies: $d \sigma_{y}^{2} / d \eta>0$.

Differentiating Equation (10) with respect to $v$, we obtain:

$$
\frac{1}{\sigma_{y}^{2}} \frac{d \sigma_{y}^{2}}{d v}=2 \underbrace{\left[\frac{1}{\tilde{y}^{*}-1} \frac{d \tilde{\mathrm{y}}^{*}}{d \nu}+\frac{\left(\tilde{\mathrm{y}}^{*}-1\right) \frac{d p^{*}}{d \nu}+p^{*} \frac{d \tilde{y}^{*}}{d \nu}}{p^{*} \tilde{\mathrm{y}}^{*}+\left(1-p^{*}\right)}\right]}_{\text {Relative income effect: }<0}+\underbrace{\left[\frac{1-2 p^{*}}{p^{*}\left(1-p^{*}\right)}\right] \frac{d p^{*}}{d v}}_{\text {Migration effect: }>0} .
$$

Direct inspection of this condition reveals that the economywide variance changes for two reasons. First, there is a negative relative income effect: a stronger congestion effect, $v$, is synonymous with a lower income, consumption and capital gap across regions: this has a negative effect on economywide inequality. Second, there is a migration effect: as region 2 becomes more attractive, some individuals relocate to this area although it is less developed. This 
has a positive effect on economywide variance as individuals who relocate incur a reduction in their consumption, capital, and income.

Interestingly, which of the effects dominates depends on the initial difference in development between the two regions: $\widetilde{A}$. Specifically, if $\widetilde{A}$ is initially low, it means that the difference in population shares between the two regions is likely to be small. In this case, the relative income effect is likely to dominate the migration effect and inequality decreases. If $\widetilde{A}$ is sufficiently high (i.e., if the difference in income, consumption, capital, and population size in the two regions is large), however, the migration effect is likely to dominate and the economywide variance will increase. This result is important when we analyze the policy implication of a positive change in $\varepsilon_{2}$.

\subsection{Policy Implications}

Here we spell out the implications of a change in economic policy on individuals' residential choice, distribution, growth, and welfare at the steady state. We distinguish between two kinds of policy change. First, we discuss the implications of a change in the overall tax rate, $\tau$, for a given relative share of public spending, $\varepsilon_{1} / \varepsilon_{2}$. Second, we analyze the impact of a change in the share of resources devoted to public infrastructure in region $2, \varepsilon_{2}$, for a given overall tax rate, $\tau$, i.e., for this latter we take the view that the government spends a greater share of public funds in the less-developed region to favor its development. ${ }^{16}$

To analyze the welfare effects of policy changes, we take as benchmark the case of a utilitarian government; the latter chooses the tax rate and the repartition across regions, denoted hereafter $\tau^{w}$ and $\varepsilon_{1}^{w}$, with $1=\varepsilon_{1}^{w}+\varepsilon_{2}^{w}$, by maximizing the weighted sum of individuals' utilities: $W_{t}=\int_{0}^{L} U_{i j, t} d i$. Assuming that the economy is in steady state at date zero, the level of lifetime utility of individual $i, i \in[0, L]$, living in region $j$ is given by:

$$
U_{i j, 0}=\ln \left(c_{i j, 0}\right) / \rho-\eta \ln \left(p_{j}^{*}\right) / \rho+g^{*} / \rho^{2} .
$$

Thus, total welfare is given by

$$
\frac{W_{0}}{L}=\left[\begin{array}{c}
\frac{p^{*}}{\rho} \ln \left\{k_{1,0}\right\}-\frac{\eta}{\rho} p^{*} \ln \left(p^{*} L\right) \\
+\frac{1-p^{*}}{\rho} \ln \left\{k_{2,0}\right\}-\frac{\eta}{\rho}\left(1-p^{*}\right) \ln \left[\left(1-p^{*}\right) L\right] \\
+\frac{1}{\rho} \ln \left[\frac{(1-\alpha)\left(g^{*}+\delta\right)+\rho}{\alpha}\right]+\frac{g^{*}}{\rho^{2}}
\end{array}\right] .
$$

We now turn to the policy implications of the model.

\subsubsection{Change in Overall Tax, $\tau$}

We analyze the effects of a change in $\tau$ on $p^{*}, \widetilde{c}^{*}, \widetilde{y}^{*}, \widetilde{k}^{*}, g^{*}, \sigma_{y}^{2}$, and $W_{0}$. Results are summarized in Table 1, which presents the signs of the derivatives of $p^{*}, \widetilde{c}^{*}, \widetilde{y}^{*}, \widetilde{k}^{*}, g^{*}, \sigma_{y}^{2}$, and $W_{0}$ with respect to $\tau$, where $\tau^{\max }$ represents the growth maximizing tax level and $\tau^{w}$ the golden rule tax level. The proofs of the results directly come from inspection of Equations (7), (8), (9), (10), and (13).

\footnotetext{
${ }^{16}$ We could alternatively consider the effects of a change in $\varepsilon_{1}$. We do not perform the analysis to avoid unpleasant redundancy. We recall that tax rates are linked at each instant through the relation: $1=\varepsilon_{1}+\varepsilon_{2}$.
}

(C) Southern Regional Science Association 2014. 
Table 1: Effects of a change in overall tax rate, $\tau$

\begin{tabular}{lllll}
\hline Derivative & $\frac{d p^{*}}{d \tau}$ & $\frac{d \widetilde{c}^{*}}{d \tau}=\frac{d \tilde{y}^{*}}{d \tau}=\frac{d \tilde{k}^{*}}{d \tau}$ & $\frac{d g^{*}}{d \tau}$ and $\frac{d W_{0}}{d \tau}$ & $\frac{d \sigma_{y}^{2}}{d \tau}$ \\
\hline Sign & $=0$ & $=0$ & $<0$ if $\tau<\tau^{\max }=\tau^{w}$ & $=0$ \\
\hline \hline
\end{tabular}

Table 1 shows that a change in the overall tax rate has no effect on the proportion of individuals in each region, $p^{*}$, and inequality, $p^{*}, \widetilde{c}^{*}, \widetilde{y}^{*}, \widetilde{k}^{*}, \sigma_{y}^{2}$. Such result is reminiscent of the finding in some urban mono-centric models and similar settings where it is argued that uniform taxation across regions overcomes interregional migration (see, e.g., Haurin, 1980; Jones, 1982). In the same line of the arguments of this literature, our result is the direct consequence of the fact that, what matters in terms of individuals' behavior and residential choice is the relative development level of regions: $\widetilde{A}=\left[A_{1}\left(\varepsilon_{1}\right)^{1-\alpha}\right] /\left[A_{2}\left(\varepsilon_{2}\right)^{1-\alpha}\right]>1$. As the relative funding, $\varepsilon_{1} / \varepsilon_{2}$, remains the same, individuals' trade-off between income (consumption) and population size is not affected by a change in $\tau$ alone.

Let us remark that the overall tax rate affects growth and welfare, however. Using Equations (9) and (13), we can show that, for a given relative repartition of funding, $\varepsilon_{1} / \varepsilon_{2}$, growth and welfare are maximum if:

$$
\tau^{\max }=\tau^{w}=1-\alpha .
$$

As Barro (1990) made it clear, this condition implies that, to maximize growth and then welfare, the government must equalize the level of the overall tax rate to the share it would obtain if public goods and services were supplied on competitive markets. The reason is that there is a trade-off between the production of public infrastructure and the quantity of output left for consumption and savings. On the one hand, a higher level of tax allows the government to produce a greater amount of public infrastructure in each region which is beneficial to growth. On the other hand, it also reflects a resource withdrawal effect, as more resources devoted to the production of public infrastructure have a negative effect on individuals' private consumption and investments. This latter is detrimental to long-term growth. Specifically, when the tax rate is low, i.e., $0<\tau<\tau^{\max }=\tau^{w}=1-\alpha$, the marginal productivity of public infrastructure is high: an additional unit of public service translates into long-run growth and, thereby, offsets the effect due to a lower amount of output devoted to physical capital accumulation. When the tax rate is high, i.e., $\tau^{\max }=\tau^{w}=1-\alpha<\tau<1$, however, the productivity of public services is low: in this case, an additional unit of resource devoted to the production of public infrastructure is growthreducing.

\subsubsection{Change in the Share of Tax Allocated to Region 2, $\varepsilon_{2}$}

In this subsection, we focus on the relative effects of a permanent increase in the share of the tax allocated to region $2, \varepsilon_{2}$, assuming that the overall tax rate, $\tau$, is fixed. The noteworthy feature of such policy is that it affects individuals' trade-off between income (consumption) and population size (congestion). When increased, region 1 (2) becomes less (more) productive, thereby less (more) attractive implying that $p^{*}, \widetilde{c}^{*}, \tilde{y}^{*}, \widetilde{k}^{*}$ decrease (see 7 and 8 ). The 
implications for growth, economywide variance and steady-state welfare are more complex. Each is analyzed in turn below.

Implications for growth: To get some intuition about the mechanisms at work regarding growth, we can use (9) to obtain:

$$
\frac{\alpha}{1-\alpha} \frac{\left(g^{*}+\delta+\rho\right)^{-1}}{L^{1-v}[\alpha(1-\tau)]^{\frac{\alpha}{1-\alpha}}} \frac{d g^{*}}{d \varepsilon_{2}}=\left\{\begin{array}{l}
\underbrace{(1-v) \frac{d p^{*}}{d \varepsilon_{2}}\left(p^{*}\right)^{-v}\left(A_{1}\right)^{1 /(1-\alpha)} \varepsilon_{1}\left(1-\frac{1}{\tilde{y}^{*}}\right)}_{\text {Migration effect: }>0 \text { as } 1<v<1 /(1-\alpha)} \\
-\underbrace{\left(p^{*}\right)^{1-v}\left(A_{1}\right)^{1 /(1-\alpha)}\left[1-\left(\tilde{y}^{*}\right)^{(v-1) / \eta}\left(\frac{A_{2}}{A_{1}}\right)^{\frac{1}{1-\alpha}}\right]}_{\text {Public Infrastructure effect: }>0 \text { or }<0}
\end{array}\right\} .
$$

Inspection of (14) allows us to identify two effects affecting long-term growth. First, there is a migration effect whereby the change of residence of individuals from region 1 to region 2 affects their choice of savings, and in turn growth: under the maintained assumption $1<v<1 /(1-\alpha)$, this effect is always positive as $\tilde{y}^{*}>1$. Second, there is a public infrastructure effect whereby a greater share of public funds allocated to region $2, \varepsilon_{2}$, induces a lower amount of public infrastructure for region 1. Under the maintained assumption $1<v<1 /(1-\alpha)$, this effect can be of either sign. Nonetheless, this effect is clearly likely to be positive for low values of $\varepsilon_{2}$. Intuitively, this is synonymous with a great income disparity between regions. Interestingly, such differences shrink as $\varepsilon_{2}$ increases. Thus, for sufficiently high values of $\varepsilon_{2}$, the public infrastructure effect is likely to be negative: in this case, the increase in public spending in region 2 and the resulting productivity gains in that region do not compensate for the productivity loss in region 1: it is growth-reducing. We thus conclude that, under the maintained assumption $1<v<1 /(1-\alpha), g^{*}$ describes an inverted-U relation with respect to $\varepsilon_{2}$, i.e., there exists a value of $\varepsilon_{2}$ which maximizes growth, denoted hereafter by $\varepsilon_{2}^{\max }$.

Implications for Inequality: Using (10), we can show that the effect of an increase of funds allocated to region 2 on the economywide level of inequality is given by:

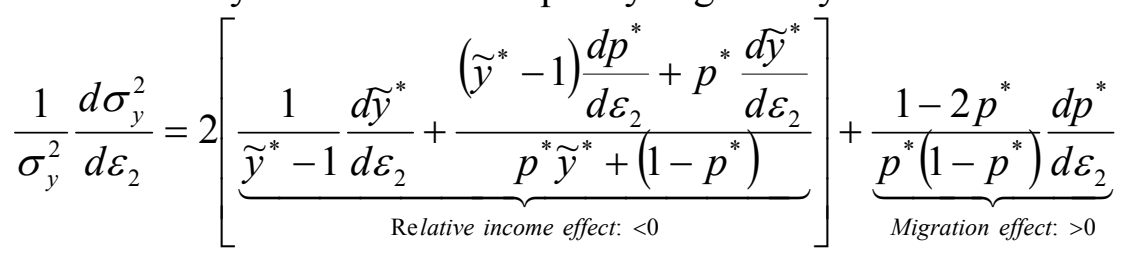

From expression (15), it appears clearly that, similar to a change in the congestion effect, $v$, a change in the share of public funds allocated to region 2 has both a relative income effect and a migration effect. More specifically, we can conclude that, if $\widetilde{A}>1$ is initially high (due, for instance, to a low initial value of $\varepsilon_{2}$ ), inequality increases. But as $\varepsilon_{2}$ takes higher values and, therefore, as more people join region 2 , the weight of region 1 in the determination of the economywide variance decreases. This effect combines with the fact that a positive change in $\varepsilon_{2}$ induces a reduction in the consumption, income and capital gap across individuals. In other words, for a sufficiently high value of $\varepsilon_{2}$, the relative income effect is likely to dominate the 
migration effect, implying that economywide inequality and the share of public funds allocated to region 2 describe an inverted-U relation.

Implications for steady-state welfare: Using (13) and the steady-state property of the model, we obtain:

$$
\frac{\rho}{L} \frac{d W_{0}}{d \varepsilon_{2}}=\left[\frac{(1-\alpha)}{(1-\alpha)\left(g^{*}+\delta\right)+\rho}+\frac{1}{\rho}\right] \frac{d g^{*}}{d \varepsilon_{2}} .
$$

In other words, from (16) we can establish the following proposition regarding the impact of a change in the share of resources allocated to region $2, \varepsilon_{2}$ :

Proposition 2: The golden rule share of resources to be allocated to region 2 necessarily equates the growth maximizing one: $0<\varepsilon_{2}^{w}=\varepsilon_{2}^{\max }<1$.

This proposition claims that, in the case of high congestion effects (i.e. $1<v<1 /(1-\alpha)$ ) like those observed in mega-cities of developing countries, allocating a greater share of public funds to poor areas is a proper policy to implement if $0<\varepsilon_{2}<\varepsilon_{2}^{w}=\varepsilon_{2}^{\max }<1$ initially. In this case, a permanent and positive change in the share of funds allocated to region $2, \varepsilon_{2}$, for a given overall tax rate, $\tau$, leads to an increase in growth and steady-state welfare. Intuitively, since individuals are identical and, hence, indifferent between the two regions, they focus on difference in the level of growth between the two regions, which affects their personal welfare perspective. This latter should therefore be set to its maximum.

Regarding inequality, we can infer that $\sigma_{y}^{2}$ is likely to decrease, especially if $\widetilde{A}>1$ is high initially. This is interesting as this scenario is synonymous of a high relative level of imbalance between regions. That is to say, it represents the situation we observe in developing countries. In this context, the result of Proposition 2 suggests, contrary to the common view, that favoring the less-developed area does not necessarily entail a trade-off between growth, long-run welfare, and equality. By increasing investment in infrastructure within the less-developed region, the government effectively favored its development via an increase in productivity of its population. Interestingly, this effect is accompanied by the migration of some individuals from the more-developed area. As a result the more-developed region becomes less congested, yielding a productivity gain there as well. Overall, the policy is beneficial not only for growth and welfare but it also helps to reduce regional imbalances (i.e., inequalities between individuals).

\section{CONCLUSION}

Introducing economic development issues together with migration and equality problems in an endogenous growth model is an important research area that we attempted to tackle in this paper. We have built a simple endogenous growth model with two heterogeneous regions in which individuals must decide where to reside and work. While one region is assumed to be more developed (i.e., more productive) and thus more attractive from the perspective of an individual's income (or consumption), it is also more crowded, which dampens overall welfare. That is, we formalized, in a straightforward manner, a trade-off between income (or consumption) and congestion. 
In such a framework, we demonstrate the key role played by the strength of congestion effects in production when a specific regional policy change is implemented. We showed that, in the face of sufficiently high output-based congestion effects, like those encountered in megacities of developing countries, favoring development in the poorer area is the proper policy to implement for most any nationwide policy goal. An important result is that there is not necessarily a trade-off between growth and welfare, on the one hand, and equality on the other hand.

For analytical tractability and for the purpose of establishing a first set of relevant results, we have opted for the simplest endogenous growth framework. As the focal point of the paper was the impact of government expenditures on the choice of location of individuals, congestion was modeled as depending on population only. A natural extension could then be to add another source of congestion: as it is standard in the literature, we could consider a congestion effect due to the stock of physical capital and examine how it affects the main results. In the future, we also plan to extend further our analysis of the link between residential choice, inequality, and growth. We believe that considering a two-sector model of endogenous growth with human capital accumulation is relevant. One reason is that population size or congestion effects are likely to affect not only individuals' productivity but also their learning abilities in various ways. In that sense, it could help to endogenize the productivity of individuals and, in turn, refine our results with respect to a possible trade-off between education (which would determine individuals' income and consumption levels) and population size.

On the empirical side, an interesting issue would be to study the magnitudes of population migration across regions, inequality, and welfare when the government attempts to favor particular areas via a policy of development of infrastructure as formalized here. Another direct policy implication is to analyze the optimal allocation of tax revenues between the regions. In each analysis, it would be necessary to calibrate the model by mapping its equilibrium conditions with actual data. ${ }^{17}$ Works by Alonso-Carrera, Freire-Seren, and Manzano (2009) and Arcalean, Glomm, and Schiopu (2012) along these lines for Spain and Portugal, respectively, could offer a starting point. Another interesting issue would be the numerical analysis of the global dynamics of the economy. In this case, it would be more appropriate to consider public capital as specified in Appendix A.2: this is closer to reality and would facilitate the matching of the model with the data.

\section{REFERENCES}

Agenor, Pierre-Richard. (2005) "Infrastructure, Public Education and Growth with Congestion Costs," The School of Economics Discussion Paper Series 0524, Economics, University of Manchester.

(2008) "Health and Infrastructure in a Model of Endogenous Growth," Journal of Macroeconomics, 30, 1407-1422.

Alonso, William. (1964) Location and Land Use. Harvard University Press: Cambridge, MA.

Alonso-Carrera, Jaime, Maria J. Freire-Seren, and Baltasar Manzano. (2009) "Macroeconomic Effects of the Regional Allocation of Public Capital Formation," Regional Science and Urban Economics, 3, 563-574.

\footnotetext{
${ }^{17}$ Also, with calibration, the model can more easily be extended to multiple regions.
}

(C) Southern Regional Science Association 2014. 
Arcalean, Calin, Gerhard Glomm and Ioana Schiopu. (2012) "Growth Effects of Spatial Redistribution Policies," Journal of Economic Dynamics and Control, 36, 988-1008.

Aschauer, David A. (1989) "Is Public Expenditure Productive?" Journal of Monetary Economics, 23, 177-200.

. (2000) "Do States Optimize? Public Capital and Economic Growth," Annals of Regional Science, 34, 343-463.

Banerjee, Abhijit and Kaivan Munshi. (2004) "How Efficiently is Capital Allocated? Evidence from the Knitted Garment Industry in Tirupur," Review of Economic Studies, 71, 19-42.

Barro, Robert J. (1990) "Government Spending in a Simple Model of Endogenous Growth," Journal of Political Economy, 98, S103-S125.

Barro, Robert J. and Xavier Sala-i-Martin. (2004) Economic Growth, $2^{\text {nd }}$ ed. MIT Press: Cambridge, MA.

Beauchemin, Kenneth R. (2001) "Growth or Stagnation? The Role of Public Education,” Journal of Development Economics, 64, 389-416.

Boarnet, Marlon. G. (1998) "Spillovers and the Locational Effects of Public Infrastructure," Journal of Regional Science, 38, 381-400.

Boyreau-Debray, Genevieve and Shang-Jin Wei. (2005) "Pitfalls of a State-dominated Financial System: The Case of China," NBER Working Paper No. 11214.

Cadena, Andres, Jaana Remes, James Manyika, Richard Dobbs, Charles Roxburgh, Heinz-Peter Elstrodt, Alberto Chaia, and Alejandra Restrepo. (2011) "Building Globally Competitive Cities: The Key to Latin American Growth,” McKinsey Global Institute, available at http://www.mckinsey.com/insights/urbanization/building_competitive_cities_key_to_latin_american_growth.

Casella. Alessandra. (2005) "Redistribution Policy: A European Model," Journal of Public Finance, 89, 1305-1331.

Ciccone, Antonio and Robert A. Hall. (1996) "Productivity and the Density of Economic Activity," American Economic Review, 86, 54-70.

de la Fuente, Angel and Xavier Vives. (1995) "Infrastructure and Education as Instruments of Regional Policy: Evidence from Spain,” Economic Policy, 20, 13-51.

Eaton, Jonathan and Zvi Eckstein. (1997) "Cities and Growth: Theory and Evidence from France and Japan," Regional Science and Urban Economics, 27, 443-474.

Evans, Paul and Georgios Karras. (1994) "Are Government Activities Productive? Evidence from a Panel of U.S. States," Review of Economics and Statistics, 76, 1-11.

Glaeser, Edward L. and Joseph Gyourko. (2005) "Urban Decline and Durable Housing," Journal of Political Economy, 113, 345-375.

Hansen, Niles. (1990) "Impacts of Small and Intermediate-sized Cities on Population Distribution: Issues and Responses," Regional Development Dialogue, 1, 60-76.

Haurin, Donald R. (1980) "The Regional Distribution of Population, Migration, Climate," Quarterly Journal of Economics, 95, 293-308.

Henderson, J. Vernon. (1982) "Evaluating Consumer Amenities and Interregional Welfare Differences," Journal of Urban Economics, 11(1), 32-59.

(C) Southern Regional Science Association 2014. 
. (2002) "Urbanization in Developing Countries," World Bank Research Observer, 17, 89112.

Hirschman, Albert O. (1958) The Strategy of Economic Development. Yale University Press: New Haven, CT.

Holtz-Eakin, Douglas. (1994) "Public Sector Capital and the Productivity Puzzle," Review of Economics and Statistics, 76, 12-21.

Holtz-Eakin, Douglas and Anna J. Schwartz. (1995) "Spatial Productivity Spillovers from Public Infrastructure," International Tax and Public Finance, 2, 459-468.

Jones, Donald W. (1982). "The Interregional Incidence of Local Taxes with Migration and a Nontradable Good," Geographical Analysis, 14, 109-123.

Krugman, Paul. (1991) "Increasing Returns and Economic Geography," Journal of Political Economy, 99, 483-499.

Krugman, Paul and Anthony Venables. (1995) "Globalization and the Inequality of Nations," Quarterly Journal of Economics, 110, 857-880.

Martin, Philippe and Giacomo I. P. Ottaviano. (2001) "Growth and Agglomeration," International Economic Review, 42, 947-968.

Mills, Edwin S. (1967) “An Aggregative Model of Resource Allocation in a Metropolitan Area," American Economic Review, 57, 197-210.

Muth, Richard F. (1969) Cities and Housing. Chicago: University of Chicago Press.

Munnell, Alicia H. (1992) "Infrastructure Investment and Economic Growth," Journal of Economic Perspectives, 6, 189-198.

Ott, Ingrid and Susanne Soretz. (2010) "Productive Public Input, Integration and Agglomeration," Regional Science and Urban Economics, 40, 538-549.

Puga, Diego. (1999) “The Rise and Fall of Regional Inequalities,” European Economic Review, $43,303-334$.

Rioja, Felix K. (1999) "Productiviness and Welfare Implications of Public Infrastructure: A Dynamic Two-sector General Equilibrium Analysis," Journal of Development Economics, 58, 387-404.

. (2005) "Roads versus Schooling: Growth Effects of Government Choices," B.E. Journals in Macroeconomics, 5, 1-24.

Roback, Jennifer. (1982) "Wages, Rents, and the Quality of Life," Journal of Political Economy, 90, 1257-1278.

Romp, Ward E. and Jakob de Haan. (2007) "Public Capital and Economic Growth: A Critical Survey," Perspektiven der Wirtschaftspolitik, 8, 6-52.

Sharma, Siddharth. (2008) "Capital Immobility and Regional Inequality: Evidence from India," Finance and Private Sector Development, The World Bank Group, available at http://www.enterprisesurveys.org/ /media/GIAWB/EnterpriseSurveys/Documents/ResearchPapers/Capital-ImmobilityIndia.pdf.

(C) Southern Regional Science Association 2014. 
Van der Ploeg, Frederick and Steven Poelhekke. (2008) "Globalization and the Rise of MegaCities in the Developing World," Cambridge Journal of Regions, 1, 477-501.

Zhang, Wei-Bin. (1997) "A Two-Region Model with Endogenous Capital and KnowledgeLocational Amenities and Preferences," International Review of Economics and Finance, $6,1-16$.

\section{APPENDIX}

\section{A.1 Proof of Proposition 1}

\section{A.1.1 Growth and inequality}

Using Equations (2), (4), and (5), we can easily check that the capital/output ratio and the consumption/capital ratio are identical for every individual:

$$
\begin{aligned}
& \frac{k_{i j, t}}{y_{i j, t}}=\frac{k_{t}}{y_{t}}=\frac{\alpha(1-\tau)}{g+\rho+\delta}, \text { for all } i \in[0, L] \text { and } j=1,2, \\
& \frac{c_{i j, t}}{k_{i j, t}}=\frac{c_{t}}{k_{t}}=\frac{(1-\alpha)(g+\delta)+\rho}{\alpha}, \text { for all } i \in[0, L] \text { and } j=1,2 .
\end{aligned}
$$

From Equations (1), (17), and (18), after simple manipulations, we obtain:

$$
\frac{k_{i j, t}}{k_{t}}=\frac{k_{j, t}}{k_{t}}=\left[\frac{\alpha(1-\tau)\left(A_{j}\right)^{1 / \alpha}}{g+\rho+\delta}\right]^{\alpha /(1-\alpha)}\left[\frac{\varepsilon_{j} \tau}{\left(p_{j} L\right)^{v}}\right], j=1,2, i \in[0, L] .
$$

Taking into account that individuals are identical, i.e. those choosing to reside in a given region obtain the same levels of consumption and capital, with the condition $\int_{0}^{L} k_{j, t} d i=p L k_{1, t}+(1-p) L k_{2, t}=k_{t}$, we get:

$$
1=\left\{\begin{array}{l}
{\left[\frac{\alpha(1-\tau)\left(A_{1}\right)^{1 / \alpha}}{g+\rho+\delta}\right]^{\alpha /(1-\alpha)}\left[\frac{\varepsilon_{1} \tau}{\left(p_{1} L\right)^{v}}\right] \int_{0}^{p_{1} L} 1 d i} \\
+\left[\frac{\alpha(1-\tau)\left(A_{2}\right)^{1 / \alpha}}{g+\rho+\delta}\right]^{\alpha /(1-\alpha)}\left[\frac{\varepsilon_{2} \tau}{\left(p_{2} L\right)^{v}}\right] \int_{p_{1} L}^{L} 1 d i
\end{array}\right\} .
$$

Simplifying this expression, we obtain (9). The economywide variance of income relative to the average, $y_{i j, t} / \overline{y_{t}}$, is given by

$$
\sigma_{y}^{2}=\operatorname{Var}\left(y_{i j, t} / \overline{y_{t}}\right)=E\left(y_{i j, t} / \overline{y_{t}}-1\right)^{2}=E_{i \mid i<p}\left(y_{1, t} / \overline{y_{t}}-1\right)^{2}+E_{i \mid i>p}\left(y_{2, t} / \overline{y_{t}}-1\right)^{2} \text {. }
$$

Trivial decomposition yields:

$$
\sigma_{y}^{2}=E_{i \mid i<p}\left[y_{1, t} / \overline{y_{t}}-\overline{y_{1, t}} / \overline{y_{t}}-\left(1-\overline{y_{1, t}} / \overline{y_{t}}\right)\right]^{2}+E_{i \mid i>p}\left[y_{2 t} / \overline{y_{t}}-\overline{y_{2, t}} / y_{t}-\left(1-\overline{y_{2, t}} / \overline{y_{t}}\right)\right]^{2},
$$

where $\overline{y_{j, t}}$ denotes the average level of income in region $j, j=1,2$. Since each parenthesis is a constant for each group of individuals separately, and using the fact that $\overline{y_{t}}=p \overline{y_{1, t}}+(1-p) \overline{y_{2, t}}$ and noting that $\overline{y_{j, t}} / \overline{y_{t}}=(p)^{1-v}\left(A_{j}\right)^{1 /(1-\alpha)} \varepsilon_{j} \tau\{\alpha(1-\tau) /[g+\rho+\delta]\}^{\alpha /(1-\alpha)}$, we can simplify this expression to obtain (10). 


\section{A.1.2 Ratios and the population share}

Recalling that $\widetilde{c}^{*} \equiv c_{i 1, t} / c_{i 2, t}, \tilde{y}^{*} \equiv y_{i 1, t} / y_{i 2, t}, \widetilde{k}^{*} \equiv k_{i 1, t} / k_{i 2, t}, i \in[0, L]$, Equations (17) and (18) imply:

$$
\widetilde{c}^{*}=\widetilde{y}^{*}=\widetilde{k}^{*} .
$$

Using Equations (1) and (6), we have:

$$
\widetilde{c}^{*}=\tilde{y}^{*}=\widetilde{k}^{*}=\left(\frac{p^{*}}{1-p^{*}}\right)^{\eta},
$$

and

$$
\frac{y_{1, t}}{y_{2, t}}=\frac{A_{1}\left(k_{1, t}\right)^{\alpha}\left[\frac{\varepsilon_{1} \tau}{\left(p^{*} L\right)^{v}}\right]^{1-\alpha}}{A_{2}\left(k_{2, t}\right)^{\alpha}\left[\frac{\varepsilon_{2} \tau}{\left[\left(1-p^{*}\right) L\right]^{v}}\right]^{1-\alpha}} .
$$

Thus, we obtain

$$
\frac{p^{*}}{1-p^{*}}=\left[\frac{A_{1}\left(\varepsilon_{1}\right)^{1-\alpha}}{A_{2}\left(\varepsilon_{2}\right)^{1-\alpha}}\right]^{\frac{1}{(v+\eta)(1-\alpha)}}
$$

and

$$
\widetilde{c}^{*}=\widetilde{y}^{*}=\widetilde{k}^{*}=\left[\frac{A_{1}\left(\varepsilon_{1}\right)^{1-\alpha}}{A_{2}\left(\varepsilon_{2}\right)^{1-\alpha}}\right]^{\frac{\eta}{(v+\eta)(1-\alpha)}}>1 .
$$

From the two previous equations, we obtain conditions (7) and (8).

\section{A.2 Public Infrastructure as a Stock}

In this section, we extend the analysis to consider the case where public infrastructure in regions 1 and 2 are stock variables. Specifically, we assume that the number of units of public infrastructure produced per unit of time in region $j, j=1,2$, is given by

$$
\dot{\gamma}_{j, t}=\varepsilon_{j} \tau y_{t}-\mu \gamma_{j, t},
$$

where $\mu>0$ accounts for the possible depreciation rate of public infrastructure, or cost of maintenance. We intentionally omit the case in which the production of public infrastructure is characterized by decreasing returns (i.e. $\dot{\gamma}_{j, t}=\left(\varepsilon_{j} \tau y_{t}\right)^{\varphi}-\mu \gamma_{j, t}$, with $0<\varphi<1$ ) as it would lead to zero growth in steady state.

With the above linear technology, the existence of a steady state with a strictly positive level of growth requires that public infrastructure in each region grow at the same rate as total output. We thus have

$$
\gamma_{j, t}=\frac{\varepsilon_{j} \boldsymbol{y}_{t}}{g^{*}+\mu}
$$

As the efficiency conditions of individuals' maximization problem are the same as in the main text (see Equations 4 and 5), we can follow the same steps to determine the shares of individuals 
in each region and the steady-state level of growth. After computations, we can show that, as in the main text, $p^{*}$ is given by (7) and the steady-state level of growth is implicitly given by

$$
\left(g^{*}+\rho+\delta\right)^{\alpha /(1-\alpha)}\left(g^{*}+\mu\right)=\left[\alpha(1-\tau)\left(A_{1}\right)^{1 / \alpha}\right]^{\alpha /(1-\alpha)} L\left\{\begin{array}{c}
p^{*}\left[\frac{\varepsilon_{1} \tau}{\left(p^{*} L\right)^{v}}\right] \\
+\left(1-p^{*}\right)\left[\frac{\varepsilon_{2} \tau}{\left[\left(1-p^{*}\right) L\right]^{v}}\right]
\end{array}\right\} .
$$

In other words, from a qualitative point of view, the steady-state results depicted in the main text are the same whether public infrastructure is treated as a flow or as a stock variable.

\section{A.3 Transitional Dynamics}

In what follows, we first derive a $3 \times 3$ linearized system in the consumption/capital ratio per representative individual in each region, $\xi_{1, t} \equiv c_{1, t} / k_{1, t}$ and $\xi_{2, t} \equiv c_{2, t} / k_{2, t}$, and in the capital ratio between representative individuals across regions, $\widetilde{k}_{t} \equiv k_{1, t} / k_{2, t} \cdot{ }^{18}$

Rearranging the technology for output and the resource constraint (see 1 and 2), we obtain

$$
(1-\tau) A_{j}\left[\frac{\varepsilon_{j}}{\left(p_{j}^{*} L\right)^{v}} \frac{\gamma_{t}}{k_{i j, t}}\right]^{1-\alpha}=\frac{c_{i j, t}}{k_{i j, t}}+\frac{\dot{k_{i j, t}}}{k_{i j, t}}+\delta .
$$

Differentiating (4) with respect to time and plugging the result in (5) yields

$$
\frac{\dot{c_{i j, t}}}{c_{i j, t}}=\alpha(1-\tau)(\tau)^{1-\alpha} A_{j}\left[\frac{\varepsilon_{j}}{\left(p_{j}^{*} L\right)^{v}} \frac{k_{t}}{k_{i j, t}} \frac{y_{t}}{k_{t}}\right]^{1-\alpha}-\delta-\rho .
$$

Noting that $k_{t}=p^{*} L k_{1, t}+\left(1-p^{*}\right) L k_{2, t}, \quad y_{t}=p^{*} L y_{1, t}+\left(1-p^{*}\right) L y_{2, t}, \quad$ after $\quad$ straightforward manipulations of the above equations, we obtain

$$
\begin{aligned}
& \frac{\dot{\xi}_{1, t}}{\xi_{1, t}}=\left\{\begin{array}{l}
\left.(\alpha-1)(1-\tau) A_{1}\left(\frac{y_{t}}{k_{t}}\right)^{1-\alpha}\left[\frac{\varepsilon_{1} \tau}{\left(p^{*} L\right)^{v}}\left(p^{*} L+\left(1-p^{*}\right) L \tilde{k}_{t}^{-1}\right)\right]^{1-\alpha}\right\}, \\
+\xi_{1, t}-\rho
\end{array}\right\} \\
& \frac{\dot{\xi}_{2, t}}{\xi_{2, t}}=\left\{\begin{array}{l}
(\alpha-1)(1-\tau) A_{2}\left(\frac{y_{t}}{k_{t}}\right)^{1-\alpha}\left[\frac{\varepsilon_{2} \tau}{\left[\left(1-p^{*}\right) L\right]^{v}}\left(p^{*} L \tilde{k}_{t}+\left(1-p^{*}\right) L\right)\right]^{1-\alpha} \\
+\xi_{2, t}-\rho
\end{array}\right\},
\end{aligned}
$$

\footnotetext{
${ }^{18}$ The dynamics of the consumption ratio between representative individuals across regions, $\widetilde{c}_{t} \equiv c_{1, t} / c_{2, t}$ is not included as its behaviour is implicitly determined by that of the capital ratio between representative individuals across regions, $\tilde{k}_{t} \equiv k_{1, t} / k_{2, t}$. See (19) and (20).
}

(C) Southern Regional Science Association 2014. 


$$
\frac{\dot{\vec{k}_{t}}}{{\widetilde{k_{t}}}_{t}}=\left\{(1-\tau)\left(\frac{y_{t}}{k_{t}}\right)^{1-\alpha}\left\{\begin{array}{l}
A_{1}\left[\frac{\varepsilon_{1} \tau}{\left(p^{*} L\right)^{v}}\left(p^{*} L+\left(1-p^{*}\right) L \widetilde{k}_{t}^{-1}\right)\right]^{1-\alpha} \\
-A_{2} \widetilde{k}_{t}^{1-\alpha}\left\{\frac{\varepsilon_{2} \tau}{\left[\left(1-p^{*}\right) L\right]^{v}}\left[p^{*} L+\left(1-p^{*}\right) L \widetilde{k}_{t}^{-1}\right]\right\}^{1-\alpha} \\
-\left(\xi_{1, t}-\xi_{2, t}\right)
\end{array}\right\}\right\},
$$

where

$$
\left(\frac{y_{t}}{k_{t}}\right)^{\alpha}=\left\{\begin{array}{l}
p^{*} L A_{1}\left(\frac{k_{1, t}}{k_{t}}\right)^{\alpha}\left\{\frac{\varepsilon_{1} \tau}{\left(p^{*} L\right)^{v}}\right\}^{1-\alpha} \\
+\left(1-p^{*}\right) L A_{2}\left(\frac{k_{2, t}}{k_{t}}\right)^{\alpha}\left\{\frac{\varepsilon_{2} \tau}{\left[\left(1-p^{*}\right) L\right]^{v}}\right\}^{1-\alpha}
\end{array}\right\} .
$$

Using $k_{t}=p^{*} L k_{1, t}+\left(1-p^{*}\right) L k_{2, t}$, we obtain:

$$
\frac{y_{t}}{k_{t}}=\frac{1}{p^{*} L \widetilde{k}_{t}+\left(1-p^{*}\right) L}\left\{\begin{array}{l}
\left(p^{*} L\right)^{1-v} A_{1}\left(\varepsilon_{1} \tau\right)^{1-\alpha} \widetilde{k}_{t}^{\alpha} \\
+\left[\left(1-p^{*}\right) L\right]^{1-v} A_{2}\left(\varepsilon_{2} \tau\right)^{1-\alpha} \widetilde{k}_{t}^{1-\alpha}
\end{array}\right\}^{1 / \alpha} .
$$

Simplifying the above $4 \times 4$ system with this last expression, we obtain:

$$
\begin{aligned}
& \frac{\dot{\xi_{1, t}}}{\xi_{1, t}}=\left\{\begin{array}{l}
(\alpha-1)(1-\tau) A_{1}\left\{\begin{array}{l}
\left(p^{*} L\right)^{1-v} A_{1}\left(\varepsilon_{1} \tau\right)^{1-\alpha} \tilde{k}_{t}^{\alpha} \\
+\left[\left(1-p^{*}\right) L\right]^{1-v} A_{2}\left(\varepsilon_{2} \tau\right)^{1-\alpha}
\end{array}\right. \\
\times\left[\frac{\varepsilon_{1} \tau}{\left(p^{*} L\right)^{v}}\right]^{1-\alpha} \tilde{k}_{t}^{(1-\alpha)} \\
+\xi_{1, t}-\rho
\end{array}\right\}, \\
& \frac{\dot{\xi_{2, t}}}{\xi_{2, t}}=\left\{\begin{array}{l}
(\alpha-1)(1-\tau) A_{2}\left\{\begin{array}{l}
\left(p^{*} L\right)^{1-\nu} A_{1}\left(\varepsilon_{1} \tau\right)^{1-\alpha} \widetilde{k}_{t}^{\alpha} \\
+\left[\left(1-p^{*}\right) L\right]^{1-\nu} A_{2}\left(\varepsilon_{2} \tau\right)^{1-\alpha}
\end{array}\right\}^{(1-\alpha) / \alpha} \\
\times\left[\frac{\varepsilon_{2} \tau}{\left[\left(1-p^{*}\right) L\right]^{v}}\right]^{1-\alpha} \\
+\xi_{2, t}-\rho
\end{array}\right\},
\end{aligned}
$$

and 


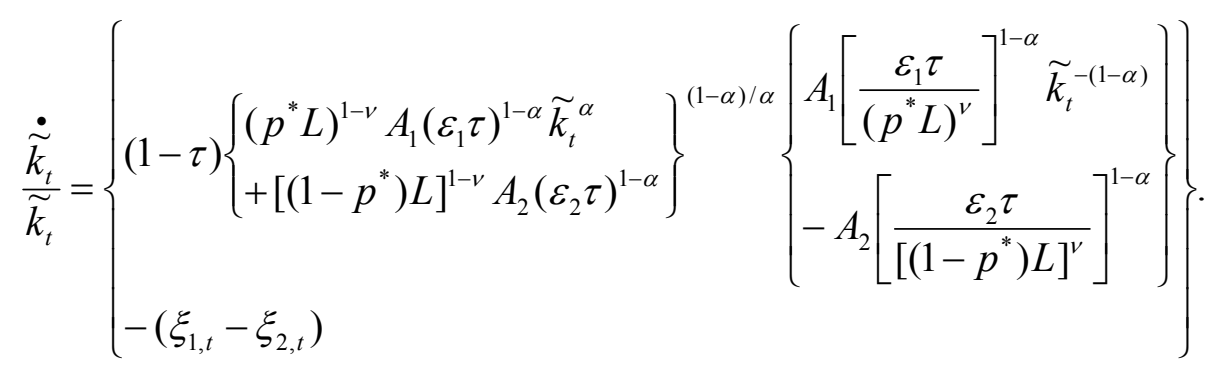

Taking a first-order Taylor approximation of the above system around the steady state, after tedious computations, we obtain:

$$
\left(\begin{array}{l}
\dot{\xi}_{1, t} / \xi_{1, t} \\
\dot{\xi}_{2, t} / \xi_{2, t} \\
\dot{\widetilde{k}}_{t} / \widetilde{k}_{t}
\end{array}\right)=M\left(\begin{array}{l}
\xi_{1, t}-\xi_{1}^{*} \\
\xi_{2, t}-\xi_{2}^{*} \\
\tilde{k}_{t}-\widetilde{k}^{*}
\end{array}\right)
$$

where the Jacobian matrix, $M$, corresponds to

$$
M=\left(\begin{array}{ccc}
1 & 0 & \Omega \\
0 & 1 & -\Omega\left(\frac{p^{*}}{1-p^{*}}\right)^{1-\alpha v} \widetilde{k}^{*} \\
-1 & 1 & -\Omega \frac{\left(\frac{p^{*}}{1-p^{*}}\right)^{1-\alpha v} \widetilde{k}^{*}+1}{1-\alpha}
\end{array}\right),
$$

and $\Omega>0$ verifies:

$$
\Omega=\left\{\begin{array}{l}
(1-\alpha)^{2}(1-\tau)\left[\left(1-p^{*}\right) L\right]^{1-v} A_{1} A_{2}\left(\varepsilon_{2} \tau\right)^{1-\alpha}\left(\tilde{k}^{*}\right)^{-(1-\alpha)-1}\left[\frac{\varepsilon_{1} \tau}{\left(p^{*} L\right)^{v}}\right]^{1-\alpha} \\
\times\left\{\left(p^{*} L\right)^{1-v} A_{1}\left(\varepsilon_{1} \tau\right)^{1-\alpha}\left(\tilde{k}^{*}\right)^{\alpha}+\left[\left(1-p^{*}\right) L\right]^{1-v} A_{2}\left(\varepsilon_{2} \tau\right)^{1-\alpha}\right\}^{(1-\alpha) / \alpha-1}
\end{array}\right\} .
$$

The characteristic equation of $M$ reads

$$
(1-q)\left\{q^{2}+q\left[\Omega \frac{\left\{\frac{p^{*}}{1-p^{*}}\right\}^{1-\alpha v} \widetilde{k}^{*}+1}{1-\alpha}-1\right]-\alpha \Omega \frac{1+\left\{\frac{p^{*}}{1-p^{*}}\right\}^{1-\alpha v} \widetilde{k}^{*}}{1-\alpha}\right\}=0 .
$$

The roots of the latter are: $q_{1}=1, \quad q_{2}=\left\{1-\Omega\left\{\left[p^{*} /\left(1-p^{*}\right)\right]^{1-\alpha v} \widetilde{k}^{*}+1\right\} /(1-\alpha)\right\} / 2+\Delta^{1 / 2} / 2$, and $q_{3}=\left\{1-\Omega\left\{\left[p^{*} /\left(1-p^{*}\right)\right]^{1-\alpha v} \widetilde{k}^{*}+1\right\} /(1-\alpha)\right\} / 2-\Delta^{1 / 2} / 2$, where the determinant, $\Delta$, is given by: $\Delta=\left\{1-\Omega\left\{\left[p^{*} /\left(1-p^{*}\right)\right]^{1-\alpha v} \widetilde{k}^{*}+1\right\} /(1-\alpha)\right\}^{2}+4 \Omega \alpha\left\{1+\left[p^{*} /\left(1-p^{*}\right)\right]^{1-\alpha v} \widetilde{k}^{*}\right\} /(1-\alpha)>0$.

(C) Southern Regional Science Association 2014. 
It is easy to see that two roots of the characteristic equation are positive while the latter is negative. Therefore, the unique steady state is (locally) saddle point stable. Indeed, the above linearized equilibrium system is characterized by one predetermined variable, $\widetilde{k}_{t} \equiv k_{1, t} / k_{2, t}$, and two non-predetermined variables, $\xi_{1, t}$ and $\xi_{2, t}$, suggesting saddle point stability around the steady state.

We now analyze the impact of an increase in $\varepsilon_{2}$ assuming that $\tau$ is fixed both on impact and along the transition, under the assumption that $\varepsilon_{2}<\varepsilon_{2}^{w}$ and that the economy is initially (i.e. at date zero) in steady state. ${ }^{19}$ This is indeed the most interesting case as a change in, $\tau$, for a given relative tax, $\varepsilon_{1} / \varepsilon_{2}$, has no effect on the relocation of individuals.

From the $M$-matrix, it readily follows that, around the steady state, the slope of $\dot{\xi}_{1, t} / \dot{\widetilde{k}}_{t}$ is negative, while the slope of $\dot{\xi}_{2, t} \dot{\widetilde{k}}_{t}$ is positive. Thus, as a control variable, on impact, the consumption-capital ratio, $\xi_{i, 0}, i \in[0, L]$, can jump up or down to a new saddle path. The noteworthy feature is that individuals living in different regions have different adjustment paths. Individuals in region 1 decrease their savings relative to their consumption. Thus, $\xi_{1, t}$ gradually increases to its new steady state. Individuals in region 2, however, have an opposite behavior. That is, $\xi_{2, t}$ gradually decreases to its new steady state. A graphical representation of the impact of a change in $\varepsilon_{2}$ on economic variables is given in Figure 1.

As for relative physical capital, which is a state variable, there is no change on impact. In subsequent periods, however, due to better public infrastructure in region 2 , and $\widetilde{k}_{0}>\widetilde{k}^{*}$, relative physical capital decreases to its new steady-state value. This means that along the transition, the level of physical capital of those in region 2 increases faster than that of those in region 1. Figure 2 below illustrates.

\section{A.4 Different Congestion Effects in Production}

We now extend the analysis to a more "general" case where the parameters measuring the regions' congestion effects in production of output are different and verify $0<v_{2}<1<v_{1}<1 /(1-\alpha)$. That is, we set the technology for output as

$$
y_{i j, t}=A_{j}\left(k_{i j, t}\right)^{\alpha}\left[\frac{\gamma_{j, t}}{\left(p_{j, t} L\right)^{\nu_{j}}}\right]^{1-\alpha} .
$$

Following the same steps as the main text, we can show, after some computations that the share of individuals in region 1 is implicitly given by:

$$
\frac{\varepsilon_{1}}{\varepsilon_{2}}\left(\frac{A_{1}}{A_{2}}\right)^{1 /(1-\alpha)} L^{v_{2}-v_{1}}=\frac{\left(p^{*}\right)^{\eta+v_{1}}}{\left(1-p^{*}\right)^{\eta+v_{2}}} .
$$

\footnotetext{
${ }^{19}$ There is no reason for a government to set $\varepsilon_{2}>\varepsilon_{2}^{w}$ which reduces welfare.
}

(C) Southern Regional Science Association 2014. 
Figure 1: Dynamics of the Consumption/Capital Ratio for Individuals in Region 1 and 2

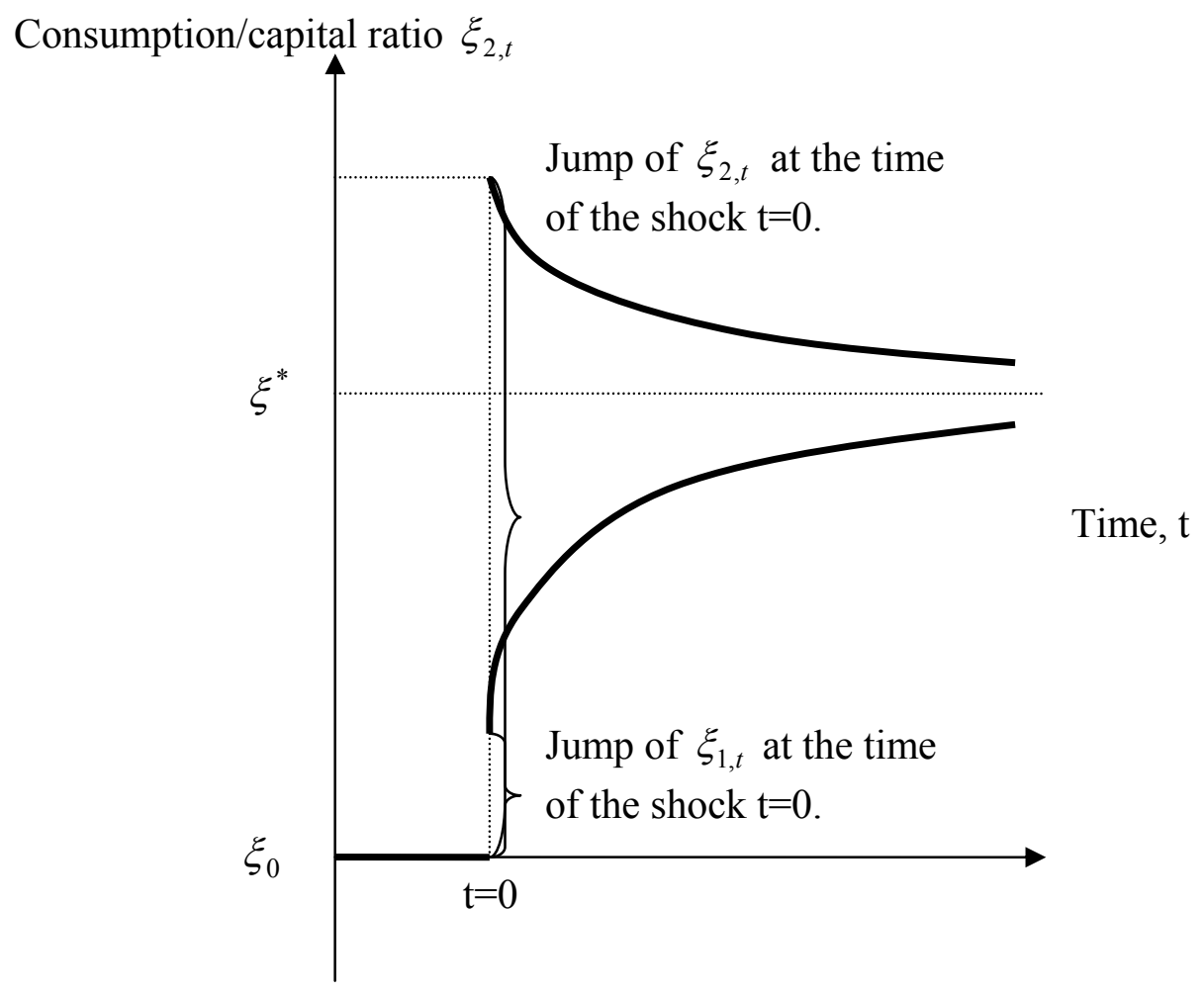

Figure 2: Dynamics of Relative Capital, $\tilde{k}_{t}$

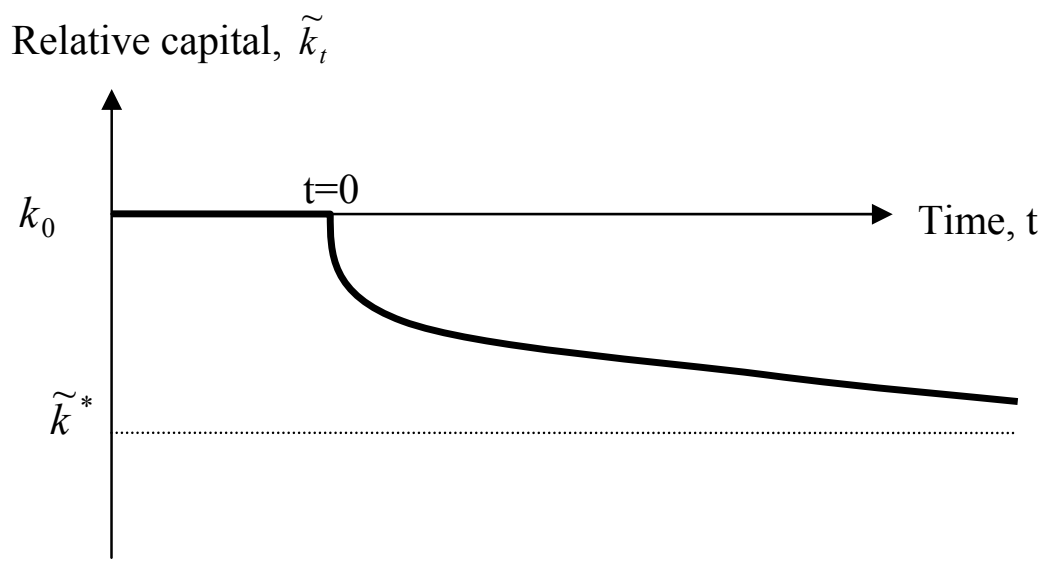

(C) Southern Regional Science Association 2014. 
Inspection of this condition shows that a unique steady-state solution for $p^{*}$ exists and is unique. Moreover, the steady-state consumption, income and capital ratios of any individual living in area 1 over any individual living in area 2 are implicitly given by:

$$
\widetilde{c}^{*}=\widetilde{y}^{*}=\widetilde{k}^{*}=\left(\frac{p^{*}}{1-p^{*}}\right)^{\eta}
$$

Finally, the steady-state level of growth is given by

$$
g^{*}=\alpha(1-\tau)\left\{\left(p^{*} L\right)^{1-v_{1}}\left(A_{1}\right)^{1 /(1-\alpha)} \varepsilon_{1} \tau+\left[\left(1-p^{*}\right) L\right]^{1-v_{2}}\left(A_{2}\right)^{1 /(1-\alpha)} \varepsilon_{2} \tau\right\}^{(1-\alpha) / \alpha}-\delta-\rho .
$$

Examination of the above equations shows that the main results of the paper still hold. Note that $d p^{*} / v_{1}<0$ for a given $v_{2}$ and $d p^{*} / v_{2}>0$ for a given $v_{1}$ as long as $p^{*} L>1$ and $\left(1-p^{*}\right) L>1$. That is, a greater (lower) congestion effect in production in region $j$ makes it less (more) attractive and leads to a migration to the other region. Analyzing the effects of a change in the part of the tax allocated to region $2, \varepsilon_{2}$, we obtain:

$$
\frac{\alpha}{1-\alpha} \frac{\left(g^{*}+\delta+\rho\right)^{\alpha /(1-\alpha)-1}}{L^{1-\nu}[\alpha(1-\tau)]^{\alpha /(1-\alpha)}} \frac{d g^{*}}{d \varepsilon_{2}}=\left\{\begin{array}{l}
\underbrace{\left(1-v_{2}\right)\left(1-p^{*}\right)^{-v_{2}}(L)^{1-v_{2}}\left(A_{2}\right)^{1 /(1-\alpha)} \varepsilon_{2} \tau \frac{d p^{*}}{d \varepsilon_{2}}\left[\frac{\left(1-v_{1}\right)}{\left(1-v_{2}\right)} \tilde{y}^{*}-1\right]}_{\text {Migration effect: }>0 \text { as } v_{2}<1 \text { and } 1<v_{1}<1 /(1-\alpha)} \\
-\underbrace{\left(1-p^{*}\right)^{1-v_{2}}(L)^{1-v_{2}}\left(A_{2}\right)^{1 /(1-\alpha)}\left[1-\frac{\varepsilon_{2}}{\varepsilon_{1}}\left(\widetilde{y}^{*}\right)^{(\eta+1) / \eta}\right]}_{\text {Public Infrastructure effect: }<0 \text { if } 1-\left(\widetilde{y}^{*}\right)^{(\eta+1) / n} \varepsilon_{2} / \varepsilon_{1}<0}
\end{array}\right\} .
$$

From this expression, we conclude that if congestion effects are strong in region 1 and low in region $2, g^{*}$ and $\varepsilon_{2}$ describe an inverted-U relation as long as $1-\left(\widetilde{y}^{*}\right)^{(\eta+1) / \eta} \varepsilon_{2} / \varepsilon_{1}<0$. 